\title{
Characteristics of Spectral Responses for a Ground Motion from Mediterranean Earthquake - ZEGHANGHANE Station (6.3Mw) in Morocco, and its Influence on the Structures
}

\author{
Mohamed AHATRI ${ }^{1}$, Khadija BABA ${ }^{1}$, Soukaina TOUIJRATE ${ }^{1}$ and Lahcen BAHI ${ }^{2}$ \\ ${ }^{1}$ GCE Laboratory, High School of Technology-Salé, Mohammed V University in Rabat-Morocco. \\ ${ }^{2} 3$ GIE Laboratory, Mohammadia Engineering School, Mohammed V University in Rabat-Morocco.
}

\begin{abstract}
The earthquakes are abrupt and sudden, and, in few seconds, they can lead to huge casualties. Nowadays, several approaches can be used to better know the seismic movement than we can expect when and where will have an earthquake. These approaches kind, always begins with a full study of the seismic action: the seismic birth, the wave formation and propagation, accelerometers and associated spectrum representation, etc.

The northern region in Morocco has an important seismic activity, indeed, this region has been struck during its history by many destructive earthquakes. In this paper, we present and discuss the Mediterranean earthquake, January 25, 2016, saved in ZGH station located in Zeghanghane near of Nador city, Morocco.

In this case, we determine the spectral response of the ground motion for ZGH station, and study his influence on the structures as well as make a comparison with the requirements of the Moroccan seismic construction regulations (RPS) 2000 revised in 2011.
\end{abstract}

\section{Introduction}

The seismic action can be described as a transitory disturbance due to the aleatory propagation of seismic waves in the soil. The motion in the given site is generally governed by three main factors: the source, the path travelled by the seismic waves and the local geotechnical conditions.

Among the seismic motion characteristics, we have the released energy which propagates in the elastic waves form. These waves are formed near of the focus and propagate towards the ground surface. There are two elastic wave types which are the compression and the shear waves, each one has its own velocity.

The aim of this study, on the one hand, is to construct and examine the spectral response of the ground motion for ZGH station [1], on the other hand, is to study his influence on structure stability which already verified by the regulations.

For that reason, in the first part, a MATLAB code is developed to read the time versus acceleration data of Mediterranean earthquake, which obtained from the Institute National Geophysics (ING) Rabat, then to solve the ordinary differential equation and give various results like accelograms, displacement response spectrum, velocity response spectrum and acceleration response spectrum.
In the second part, we studied the structure stability, which composed of a ground floor, 4 floors and an under floor, with respect to the requirements of the Moroccan seismic construction regulations (RPS) 2000 revised in 2011 [2] and with respect to the real acceleration response spectrum saved in ZGH station [1] in order to perform a comparison between them.

\section{Structure Analysis under a seismic action}

\subsection{Structure design}

During an earthquake, the structure behaviour is mainly related to the vibrations generated by the latter. In this sense, the structure seismic analysis allows to determine the seismic forces acting in both the horizontal directions and the maximum deformations that this structure can withstand.

In order to design the building structure for resisting to earthquakes, two approaches exist [3]:

- The static approach equivalent, applicable only for the regular buildings with low and medium height. This approach is based on the static solicitations calculation from the forces system in the earthquake direction, and whose effects are equivalent to those of the seismic action. 
- The dynamic approach is based on the maximum response of the structure by means of the response spectra adapted to the construction site and a direct calculation according to the time using an accelerograms adapted to the construction site. This approach is accepted when the building height and the regularity conditions required by the static approach are not satisfied.

\subsection{Moroccan seismic construction regulations (RPS) 2000 revised in 2011}

Following the Seismic construction regulations (RPS) 2000 revised in 2011, the earthquake evaluation on a structure is carried out using the following parameters:

- The maximum soil acceleration Amax obtained from the seismic zoning (article 5.2.2 of the RPS2000) is: $A \max (\mathrm{Z} 0)=0.04 \mathrm{~g} ;$ Amax $(\mathrm{Z1})=0.07 \mathrm{~g}$; Amax $(\mathrm{Z} 2)$ $=0.10 \mathrm{~g} ; \operatorname{Amax}(\mathrm{Z3})=0.14 \mathrm{~g} ; \operatorname{Amax}(\mathrm{Z} 4)=0.18 \mathrm{~g}$, with an occurrence probability of $10 \%$ in 50 years [2];

- The maximum soil velocity Vmax obtained from the seismic zoning (article 5.2.2 of the RPS2000) is: $\operatorname{Vmax}(\mathrm{Z} 0)=0,05 \mathrm{~m} / \mathrm{s} ; \quad \operatorname{Vmax}(\mathrm{Z} 1)=0,07 \mathrm{~m} / \mathrm{s}$; $\operatorname{Vmax}(Z 2)=0,10 \mathrm{~m} / \mathrm{s} ; \quad \operatorname{Vmax}(Z 3)=0,13 \mathrm{~m} / \mathrm{s}$; $\operatorname{Vmax}(\mathrm{Z} 4)=0,17 \mathrm{~m} / \mathrm{s}$, with an occurrence probability of $10 \%$ in 50 years [2];

- A response spectrum in terms of acceleration for the horizontal motion relative to a type of site normalized to the unit acceleration;

- A response spectrum of vertical motion (2/3 of the horizontal spectrum).

The elastic response spectrum or computational spectrum is defined in the RPS2000 revised in 2011 for a relative damping $\xi=5 \%$ (reinforced concrete structures and metal frames with heavy external walls and partitions) by: $\mathrm{A}(\mathrm{T})=($ Amax / g $) \mathrm{D}(\mathrm{T})$ [2] where $\mathrm{g}$ is the acceleration of gravity and $\mathrm{D}(\mathrm{T})$ the dynamic amplification factor (art.5.2.3.3 of the RPS2011 [2]). It represents the amplification of the accelerations in the structure compared to that of the ground.

Other parameters are involved in the elastic response spectrum to take account of the site effect $(S$, art.5.2.3.2 of the RPS2011 [2]), the importance coefficient (I, article 3.1.2 of the RPS2011 [2]) and the damping $(\mu=(5 / \xi) 0.4$, article 5.2.3.3 (d) of the RPS2011 [2]). The inelastic response spectrum is obtained by applying an acceleration reduction factor called the behaviour factor or ductility coefficient $(\mathrm{K}$, Art.3.3.4 of the RPS2011 [2]) as A (T) $=($ Amax / g) D (T) / K [2].

\section{Response spectra by the Duhamel integration method}

The response spectra of in acceleration, velocity and / or displacement allows to involve the notion of frequency movement content. Its purpose is to characterize an earthquake based on the response of a simple structure. By definition, an acceleration response spectrum is the curve giving the maximum acceleration of simple oscillators at a variable degree of freedom and natural frequency. Such an oscillator is shown in the figure 1 , it is characterized by a mass $\mathrm{m}$, a stiffness $\mathrm{k}$ and a damper $\mathrm{C}$.

The motion equation of forced oscillations after the earthquake application in the accelerogram ag(t) form will be the following [4]:

$$
\mathrm{ma}(\mathrm{t})+\mathrm{Cv}(\mathrm{t})+\mathrm{kD}(\mathrm{t})=-\mathrm{ma}_{\mathrm{g}}(\mathrm{t})
$$

The differential equation resolution makes it possible to know the maximum acceleration undergone by the mass $\mathrm{M}$.

Taking into account the damping definition $\zeta$, the equation can be written in the form [5]:

$$
\mathrm{a}(\mathrm{t})+2 \omega v \zeta(\mathrm{t})+\omega^{2} d(\mathrm{t})=-\mathrm{a}_{\mathrm{g}}(\mathrm{t})
$$

Where:

$$
\begin{gathered}
\mathrm{T}=2 \pi \sqrt{\frac{\mathrm{m}}{\mathrm{k}}} \\
\mathrm{f}=\frac{1}{\mathrm{~T}} \\
\omega=\frac{2 \pi}{\mathrm{T}}=2 \pi \mathrm{f}
\end{gathered}
$$

$\mathrm{k}$ : The system stiffness second)

$\omega$ : The non-damped system pulsation (in radian /

T : Period (in seconds); the motion being periodic, the cycle duration is called the motion period;

$\mathrm{f}$ : Frequency (in hertz);

The solution is given by Duhamel's integral. The relative displacement is obtained [5]:

$$
\begin{gathered}
d(t)=-\frac{1}{\omega_{D}} \int_{0}^{t} a_{g}(\tau) e^{-\zeta \omega(1-\tau)} \sin \omega_{D}(t-\tau) d \tau \\
\omega_{D}=\omega \sqrt{1-\zeta^{2}}: \text { Pseudo-pulsation of the free }
\end{gathered}
$$
oscillations damped;

\section{$\tau$ : Integration variable.}

It notes that the displacement value depends only on the pulsation $\omega$, on the damping coefficient $\zeta$ and on the ground acceleration $\mathrm{a}_{\mathrm{g}}$.

The structures having always a very low damping, we can consider that $\omega_{\mathrm{D}}=\omega$, which corresponds to a very little damped oscillator; in neglecting the secondary terms, the seismic motion components become:

The relative displacement [5]:

$$
d(t)=-\frac{1}{\omega} \int_{0}^{t} a_{g}(\tau) e^{-\zeta \omega(1-\tau)} \sin \omega(t-\tau) d \tau
$$

The relative velocity [5]:

$$
v(t)=-\int_{0}^{t} a_{g}(\tau) e^{-\zeta \omega(1-\tau)} \cos \omega(t-\tau) d \tau
$$

The pseudo-acceleration [5]:

$$
a(t)=+\omega \int_{0}^{t} a_{g}(\tau) e^{-\zeta \omega(1-\tau)} \sin \omega(t-\tau) d \tau
$$

The formulas below with the earthquake registration (accelerogram) allow to calculate systematically for all simple oscillators possible (i.e. for the whole periods range and possible damping) the maximum response values in the displacements terms $[\mathrm{d}(\mathrm{t})]$ max and draw the corresponding graphics, called responses spectra travel. Similarly, we can draw the maximum responses in the velocity terms $[v(t)] \max$ and the acceleration $[\mathrm{a}(\mathrm{t})] \max$. 
The displacement response spectra [5]:

$$
\mathrm{S}_{\mathrm{d}}=[\mathrm{d}(\mathrm{t})]_{\max }=\mathrm{S}_{\mathrm{v} / \omega}=\mathrm{D}_{\max }
$$

The velocity response spectra [5]:

$$
\mathrm{S}_{\mathrm{v}}=[\mathrm{v}(\mathrm{t})]_{\max }=\omega \mathrm{S}_{\mathrm{d}}
$$

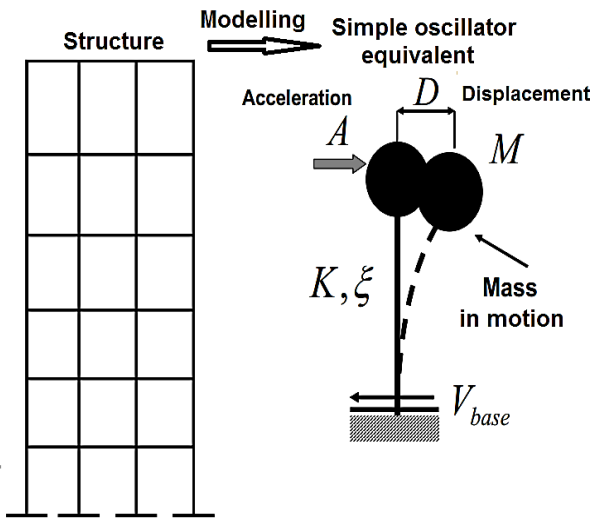

Fig. 1. Simple oscillator [3]

The acceleration response spectra [5]:

$\mathrm{S}_{\mathrm{a}}=[\mathrm{a}(\mathrm{t})]_{\max }=-\omega^{2} \mathrm{~d}(\mathrm{t})=\omega \mathrm{S}_{\mathrm{v}}=\omega^{2} \mathrm{~S}_{\mathrm{d}}$

\section{Case study}

A strong earthquake occurred at 04:22 am on 25th January 2016 in the Mediterranean between Morocco and Spain [6], which affected the Nador and El Hoceima coasts [1]. It had a moment magnitude of 6.3 in Richter scale. The epicentre was located at 35.586, -3.690, and the depth was located at $26 \mathrm{~km}$ [1].

In its initial assessment of the quake's impact, USGS said there was "a low likelihood of casualties and damage".

In this paper, we studied a structure component of a ground floor, 4 floors and an under floor by seismic analysis according to the RPS 2000 revised 2011, as well as by spectral analysis using the Mediterranean earthquake response spectra (ZGH station). We performed both analyses using the Robot Analysis software which works by the finite Element method.

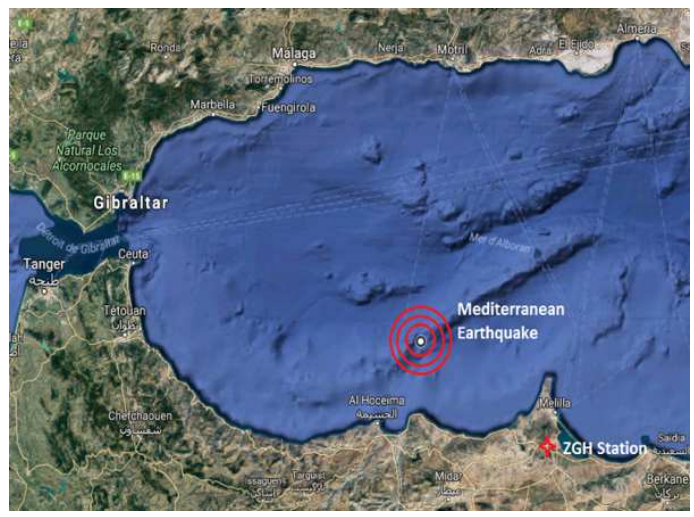

Fig. 2. The locations of the Mediterranean earthquake and the ZGH station

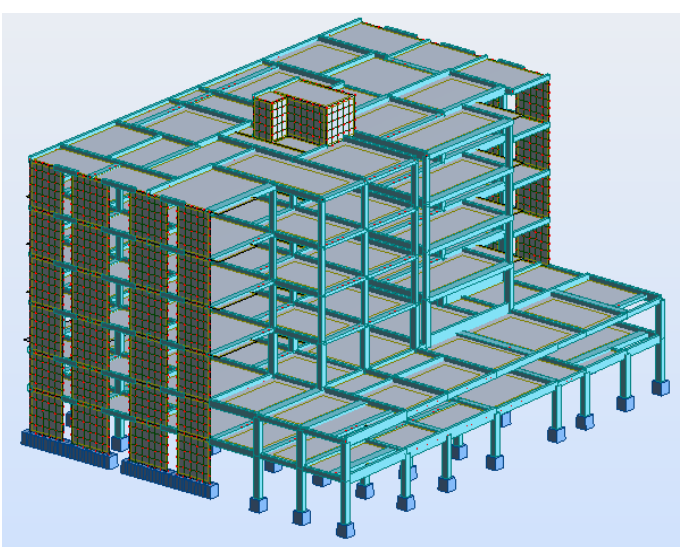

Fig. 3. The structure studied

\section{Results et discussion}

\subsection{Acceleration}

Based on the seismic inputs of Mediterranean earthquake (ZGH Station), the acceleration response is obtained.

The figure 1 shows the acceleration history time of the Mediterranean earthquake (ZGH Station).

For East, the maximum acceleration is $0.621 \mathrm{~g}$ at $17.785 \mathrm{~s}$ and the minimum acceleration is $-0.542 \mathrm{~g}$ at $18.85 \mathrm{~s}$

For North, the maximum acceleration is $0.458 \mathrm{~g}$ at $18.245 \mathrm{~s}$ and the minimum acceleration is $-0.3152 \mathrm{~g}$ at $17.075 \mathrm{~s}$.

\subsection{The response spectra of the ZGH Station}

Using a MATLAB program which developed to solve the ordinary differential equation with the time history records of the earthquake Mediterranean. The response spectra are obtained.

The spectrum taken directly from the accelerogram shows a series of irregular peaks. However, the spectral displacements increase with period, thus, the spectral velocities and accelerations, as expected, show a variation in their tendency with a decrease of the period.

The figures show the response spectra of $5 \%$ damping.

From an engineering point of view, the infrastructure designers are more concerned with the structures response in the frequency range between 1 and $10 \mathrm{~Hz}$ [7]. Thus, the amplification factors of the ground motion elevated to this frequency range play an important role in seismic disasters.

Finally, depending on the derived equations $(11,12$, 13) [5], the differential motion response spectra can be obtained for any time interval. 


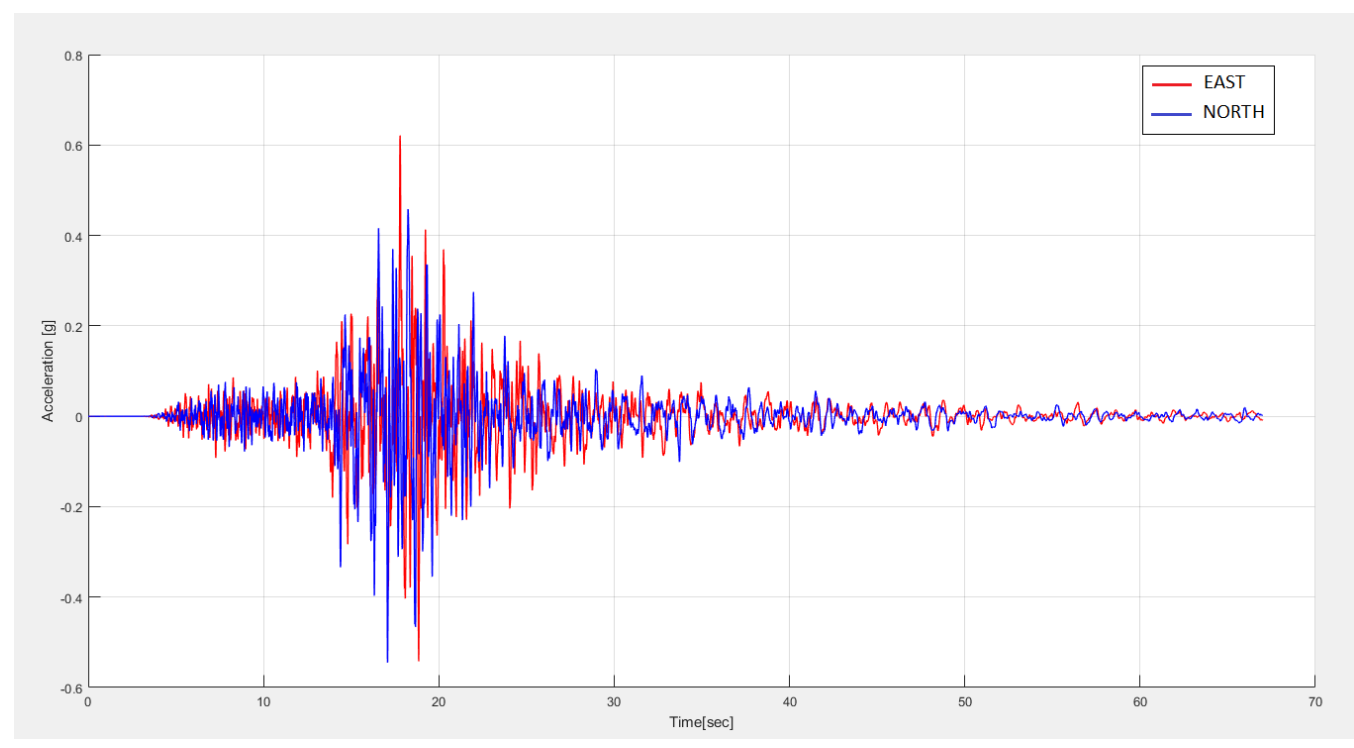

Fig. 4. Acceleration history time

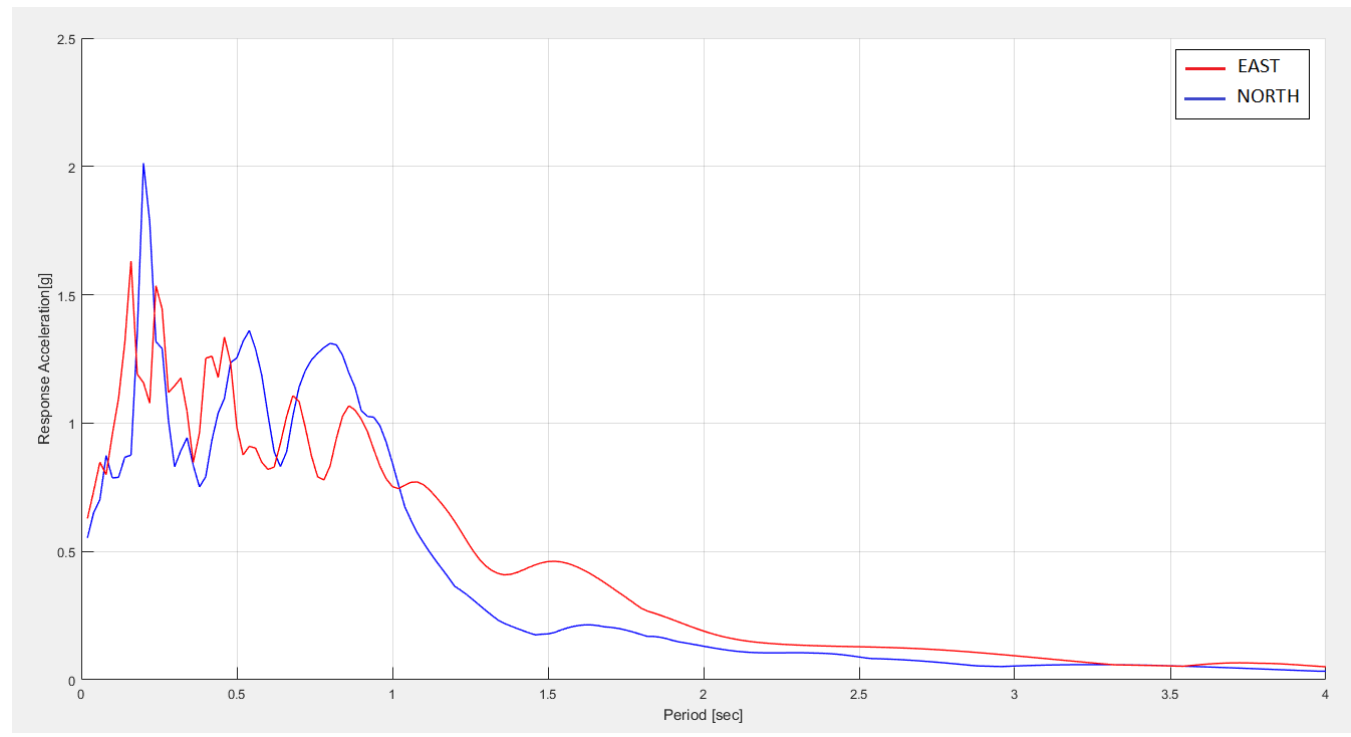

Fig. 5. Acceleration response spectrum (Sa)

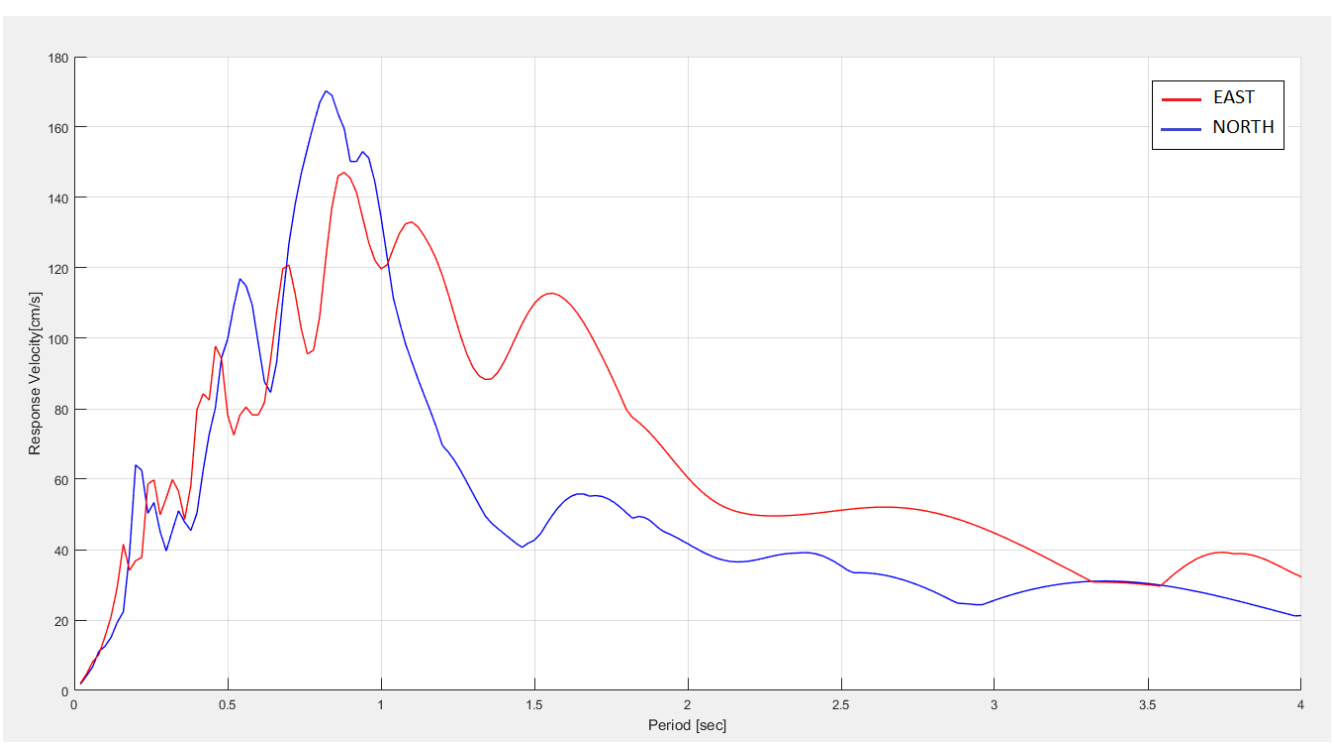

Fig. 6. Velocity response spectrum (Sv) 


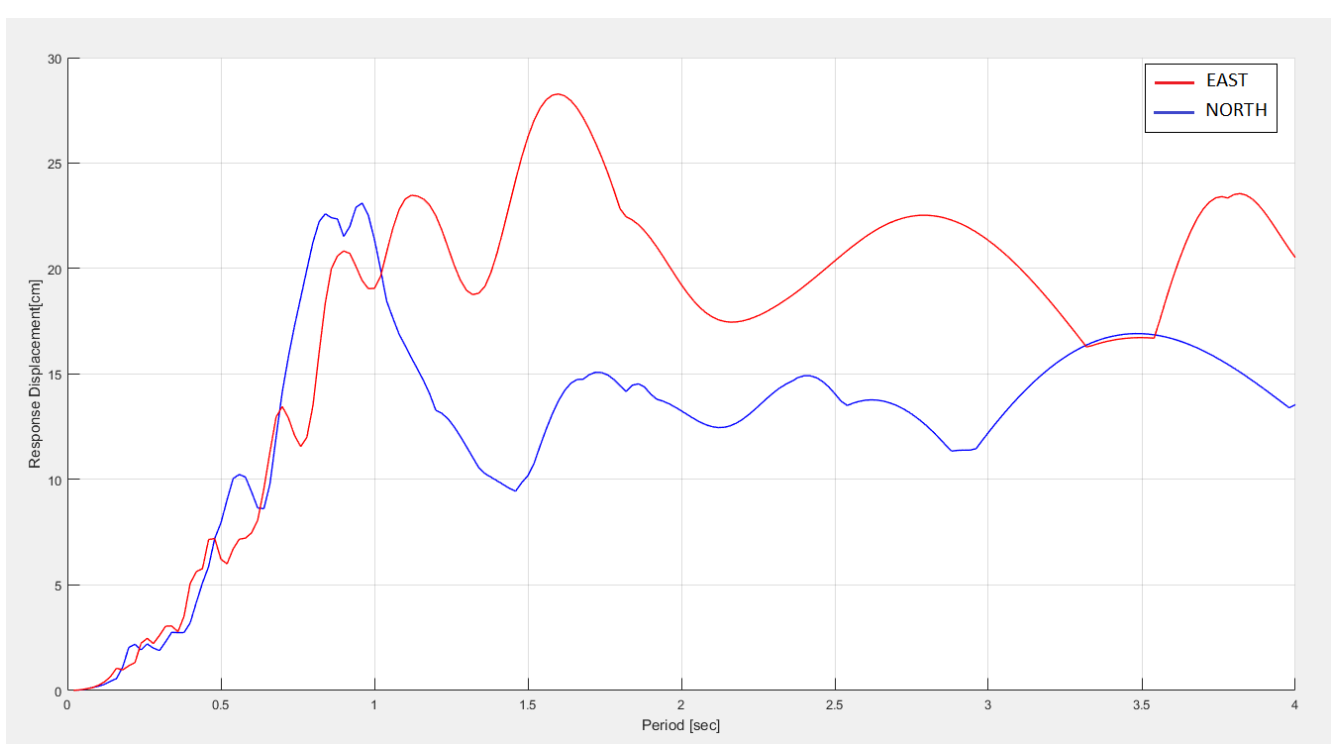

Fig. 7. Displacement response spectrum (Sd)

\subsection{The response spectra influence on structures}

Using a Robot Structural Analysis software, the displacements, the reactions, the deflections and the forces are obtained.

Using the structure study based on the spectral method by the Duhamel integration, and the study of the same structure according to the RPS2011 by the Robot Structural Analysis software most used in Morocco for the structures design which uses the finite elements method, we had been able to see the differences between the deformations and the solicitations of the elements.

As shown in the tables below, a difference between the total displacements between the study by the seismic regulation 2011 and the study by the spectral analysis on the ZGH Station of $5 \mathrm{~cm}$ according to $\mathrm{X}$ is $0.9 \mathrm{~cm}$ and

according to $\mathrm{Y}$ we also note a slight difference between inter-floor displacements.

For the whole of deformations and solicitations, the maximum values of the spectral analysis are always lower than the maximum values of the seismic analysis by the RPS 2011, with the exception of the reactions and efforts which in the worst case is the ultimate limit state that depends only on the permanent and farms loads, so it remains the same values for the two types of analysis.

Table 1. Structure deflections values according to the two analysis types

\begin{tabular}{|c|c|c|c|c|}
\hline $\begin{array}{c}\text { Analysis } \\
\text { types }\end{array}$ & Values & $\mathbf{U x}[\mathbf{c m}]$ & $\mathbf{U y}[\mathbf{c m}]$ & $\mathbf{U z}[\mathbf{c m}]$ \\
\hline $\begin{array}{c}\text { Seismic } \\
\text { RPS 2011 }\end{array}$ & Max & 0.0 & 0.9 & 8.1 \\
\cline { 2 - 5 } & Min & -0.0 & -1.2 & -5.1 \\
\hline $\begin{array}{c}\text { Spectral } \\
\text { ZGH } \\
\text { Station }\end{array}$ & Max & 0.0 & 0.4 & 8.1 \\
\cline { 2 - 5 } & Min & -0.0 & -0.6 & -5.1 \\
\hline
\end{tabular}

Table 2. Structure forces values according to the two analysis types

\begin{tabular}{|c|c|c|c|c|c|c|c|}
\hline $\begin{array}{c}\text { Analysis } \\
\text { types }\end{array}$ & Values & $\mathbf{F x}[\mathbf{T}]$ & $\mathbf{F y}[\mathbf{T}]$ & $\mathbf{F z}[\mathbf{T}]$ & $\mathbf{M x}[\mathbf{T m}]$ & $\mathbf{M x}[\mathbf{T m}]$ & $\mathbf{M x}[\mathbf{T m}]$ \\
\hline $\begin{array}{c}\text { Seismic } \\
\text { RPS 2011 }\end{array}$ & Max & 336.10 & 17.29 & 147.82 & 107.54 & 104.08 & 16.87 \\
\cline { 2 - 8 } & Min & -16.42 & -0.97 & -142.78 & -104.46 & -187.03 & -1.20 \\
\hline $\begin{array}{c}\text { Spectral } \\
\text { ZGH Station }\end{array}$ & Max & 336.10 & 9.41 & 147.82 & 107.54 & 104.08 & 15.05 \\
\cline { 2 - 8 } & Min & -16.42 & -9.19 & -142.78 & -104.46 & -187.03 & -14.45 \\
\hline
\end{tabular}

Table 3. Structure reactions values according to the two analysis types

\begin{tabular}{|c|c|c|c|c|c|c|c|}
\hline $\begin{array}{c}\text { Analysis } \\
\text { types }\end{array}$ & Values & $\mathbf{F x}[\mathbf{T}]$ & $\mathbf{F y}[\mathbf{T}]$ & $\mathbf{F z}[\mathbf{T}]$ & $\mathbf{M x}[\mathbf{T m}]$ & $\mathbf{M x}[\mathbf{T m}]$ & $\mathbf{M x}[\mathbf{T m}]$ \\
\hline Seismic & Max & 28.55 & 13.67 & 336.10 & 4.87 & 5.78 & 0.38 \\
\cline { 2 - 8 } RPS 2011 & Min & -2.33 & -4.47 & -14.96 & -1.13 & -1.02 & -0.03 \\
\hline $\begin{array}{c}\text { Spectral } \\
\text { ZGH Station }\end{array}$ & Max & 13.82 & 7.35 & 336.10 & 2.49 & 3.05 & 0.20 \\
\cline { 2 - 8 } & Min & -6.88 & -6.90 & -48.04 & -1.61 & -1.65 & -0.11 \\
\hline
\end{tabular}


Table 4 : Displacements global values according to the two analysis types

\begin{tabular}{|c|c|c|c|c|c|c|c|}
\hline $\begin{array}{c}\text { Analysis } \\
\text { types }\end{array}$ & Values & $\mathbf{U x}[\mathbf{c m}]$ & $\mathbf{U y}[\mathbf{c m}]$ & $\mathbf{U z}[\mathbf{c m}]$ & $\mathbf{R x}[\mathbf{R a d}]$ & $\mathbf{R y}[\mathbf{R a d}]$ & $\mathbf{R z}[\mathbf{R a d}]$ \\
\hline Seismic & Max & 10.2 & 4.5 & 3.1 & 0.019 & 0.081 & 0.014 \\
\cline { 2 - 8 } RPS 2011 & Min & -0.7 & -0.1 & -87.7 & -0.171 & -0.069 & -0.001 \\
\hline Spectral & Max & 5.2 & 3.6 & 3.1 & 0.019 & 0.081 & 0.008 \\
\cline { 2 - 8 } ZGH Station & Min & -2.8 & -3.5 & -87.7 & -0.171 & -0.069 & -0.008 \\
\hline
\end{tabular}

Table 5. Displacements inter-floor values according to the two analysis types

\begin{tabular}{|c|c|c|c|}
\hline Analysis types & Nodes & $\mathbf{U x}[\mathbf{c m}]$ & $\mathbf{U y}[\mathbf{c m}]$ \\
\hline Seismic RPS & 121 & 7.0 & 1.2 \\
\cline { 2 - 4 } 2011 & 141 & 7.6 & 1.5 \\
\hline Spectral ZGH & 121 & 2.5 & 0.4 \\
\cline { 2 - 4 } Station & 141 & 2.4 & 0.5 \\
\hline
\end{tabular}

\section{Conclusion}

The Robot structural analysis software, based on the finite element method, has been developed and improved for structural calculation, in which $5 \%$ damping has been considered for soil and structures.

In our case study, we found a difference between the two analyses, the first being based on the Seismic construction regulations and the second on the response spectrum, this difference in the global and inter-floor displacements, the deflections and the reactions shows that the results of the analysis by introducing a response spectrum of a real case satisfied the requirements of the seismic regulation.

On the other hand, the study shows the importance of studying and analysing the structures by response spectra recorded by accelerograms in addition to the Seismic construction regulations in order to have a general idea on the structures behaviour in an earthquake loading. The important strategic structures such as bridges and long-term administrative buildings, such as hospitals, are the structures most expected to undergo these movements. This is the case of structures near of the earthquake epicentre.

Taking into account the results, it is obvious that other studies of the influence of real response spectra on soils and structures are necessary, in order to improve Moroccan seismic construction regulation.

\section{References}

1. ING: Institute National Geophysics, RabatMorocco.

2. RPS2000 révisé 2011. (Applicable aux bâtiments). Ministère de l'aménagement du territoire, de l'urbanisme, de l'habitat et de l'environnement, Secrétariat d'Etat à l'Habitat, 78 p.

3. Youssef BELMOUDEN. Analyse spectrale non itérative des oscillateurs simples sous l'action des tremblements de terre. Bulletin de l'Institut Scientifique, Rabat, section Sciences de la Terre, 2004, n²6, 1-10.

4. Alain PECKER, livre de Dynamique des sols, Presse de l'école nationale des Ponts et Chaussées 1984.
5. Steven L. Kramer. Geotechnical Earthquake Engineering. Prentice Hall. Upper Saddle River, New Jersey 07458.

6. USGS : US Geological Survey.

7. A.K. Abd El-Aal, Ground motion prediction from nearest seismogenic zones in and around greater cairo area, Egypt, Natural Hazards and Earth System Sciences 10 (2010) 1495-1511.

8. Mohamed I.S. Elmasry. Response spectra for differential motion of structures supports during earthquakes in Egypt. Housing and Building National Research Center Journal (2012) 8, 217227".

9. B. Madani, F. Behnamfar, H. Tajmir Riahi. Dynamic response of structures subjected to pounding and structure-soil-structure interaction. Soil Dynamics and Earthquake Engineering 78 (2015) 46-600.

10. ALLIN CORNELL. ENGINEERING SEISMIC RISK ANALYSIS. Bulletin of the Seismological Society of America. Vol. 58, No. 5, pp. 1583-1606. October, 1968.

11. Chopra A.K. 1995 Dynamics of structures, theory and applicationto earthquake engineering. Prentice Hall, Englewood Cliffs, New Jersey.

12. Juan C. Reyes, Luis Ardila-Bothia, J. Paul SmithPardo, J. Nicolás Villamizar-Gonzalez, Oscar A. Ardila-Giraldo. Evaluation of the effect of containers on the seismic response of pile-supported storage structures. Engineering Structures 122 (2016) 267-278.

13. Xiaolan Pan, Zhi Zheng, Zhenyu Wang. Estimation of floor response spectra using modified modal pushover analysis. Soil Dynamics and Earthquake Engineering 92 (2017) 472-487.

14. A. Douiri, T. Mourabit, A. Cheddadi, M. Chourak, S. Louhibi. Spectral coincidences of background noise between soil and existing buildings in Imzouren city, Morocco. Journal of Materials and Environmental Science (2015). p366-376.

15. A.F. Drennov, V.I. Dzhurik, S.P. Serebrennikov, E.V. Bryzhak, N.N. Drennova. Acceleration response spectra for the earthquakes of the southwestern flank of the Baikal Rift Zone. Russian Geology and Geophysics 54 (2013) 223-230.

16. A.F. Drennov, V.I. Dzhurik, S.P. Serebrennikov, E.V. Bryzhak, N.N. Drennova. The basic parameters of acceleration spectra for $M \geq 5$ earthquakes in the Baikal Rift Zone. Russian Geology and Geophysics 56 (2015) 773-781.

17. Bilal Ahmad and Imtiyaz Akbar Najar. Comparative Seismic Analysis of EL Centro and Japan Earthquakes using Response Spectra Method. 
International Journal of Current Engineering and Technology. Vol.6, No.5 (Oct 2016).

18. Kiureghian, A., Neuenhofer, A. 1992 Response spectrum method for multisupport seismic excitations. Earthquake Engineering and Structural Dynamics 21(8) 713-740.

19. Lukas Moschen, Christoph Adam, Dimitrios Vamvatsikos. A response spectrum method for peak floor acceleration demands in earthquake excited structures. Probabilistic Engineering Mechanics 46 (2016) 94-106.

20. M. Mouzzoun, O. Moustachi, A. Taleb. Assessment of the behaviour factor for seismic design of reinforced concrete buildings. Journal of Materials and Environmental Science (2013). p23-32.

21. Masumi Yamada; et al. (2010). Spatially Dense Velocity Structure Exploration in the Source Region of the IwateMiyagi Nairiku Earthquake. Seismological Research Letters v. 81; no. 4;.Seismological Society of America. pp. 597-604.

22. Newmark N.M. \& Hall W. J. 1982 Earthquake spectra and design. Earthquake Engineering Institute.

23. Shinozuka, M. 1970 Maximum structural response to seismic excitations. Journal of Engineering Mechanics Division (ASCE) 96 729-738.

24. Thomas Wagener, Katsuichiro Goda, Mustafa Erdik, James Daniell,Friedemann Wenzel. A spatial correlation model of peak ground acceleration and response spectra based on data of the Istanbul Earthquake Rapid Response and Early Warning System. Soil Dynamics and Earthquake Engineering 85 (2016) 166-178.

25. Trifunac, M., Gicev, V. 2006 Response spectra for differential motion of columns paper II : Out-ofplane response. Soil Dynamics and Earthquake Engineering 26(12) 1149-1160. 